\title{
Entre o digital e o manual: o papel do designer contemporâneo
}

\section{Between digital and handcrafted production: the role of the contemporary designer}

\author{
BASTOS, Victoria Fernandez, Mestre, UNIPÊ - Centro Universitário de João Pessoa \\ vickfb@gmail.com
}

FERNANDES, Yasmin Mariani de Moura e Campos, Mestre, Universidade Federal de Pernambuco

fernandes.yah@gmail.com

\section{Resumo}

O presente trabalho reflete sobre o papel do designer contemporâneo diante das possibilidades projetuais e produtivas disponíveis na atualidade. Levando em consideração as mudanças da atividade durante seu desenvolvimento desde a Revolução Industrial e como o processo produtivo impacta na atuação do designer, são apresentados exemplos de abordagens distintas para ilustrar sua pluralidade. Buscou-se mostrar que a criatividade e capacidade de conceber e executar um projeto não se limitam a um caminho único.

Palavras Chave: design contemporâneo; complexidade; fabricação digital; slow design.

\begin{abstract}
The present work reflects on the role of the contemporary designer in face of the productive possibilities available today. Taking into account the changes of the activity during its development since the Industrial Revolution and how the productive process impacts on the performance of the designer, here are presented examples of distinct approaches to illustrate their plurality. It was aimed to show that creativity and the ability to design and execute a project are not limited to a single path.
\end{abstract}

Keywords: contemporary design; complexity; digital fabrication; slow design. 


\section{O papel do Designer Contemporâneo}

A relação tradicional entre o design de produto e a produção de novos artefatos vem sendo constantemente modificada ao longo dos anos, e com isso é possível observar novas abordagens surgindo. Seja através da introdução de novas tecnologias, tendências ou demandas do consumidor, o fato é que o designer contemporâneo se vê imerso em novos "problemas" ou "exigências" de uma sociedade cada vez mais complexa, desenvolvendo meios diversos para que exerça o projeto de produto.

A humanidade se depara com questões que não eram tão relevantes há tempos atrás, como preocupações com o meio ambiente e qualidade de vida, que inevitavelmente afetam os processos de produtivos e o consumo de sua produção. Conscientes das questões éticas e climáticas, os consumidores buscam produtos que agridam menos o ambiente, de produção livre da exploração do trabalho e feitos de materiais de boa procedência.

Além disso, o desenvolvimento tecnológico também entra nesta conta. A disponibilidade de matéria-prima e de processos produtivos ao designer nunca foi tão diversa, e a expansão das fronteiras e a troca de conhecimento conseguidas com a globalização aumentam ainda mais as possibilidades de configuração dos artefatos. Da mesma forma, tal variedade afeta as relações do produto com seus consumidores, o que também exerce influência sobre estes processos.

Para tais reflexões, é preciso dissociar o design e o papel do designer da definição que habita o senso comum, ligada estritamente à indústria de produção de grandes tiragens. Uma vez que a ideia seja materializada, ainda falaremos de design. Nas palavras de Löbach (2001), o design compreende a concretização de uma ideia em forma de projetos ou modelos através da construção e configuração, que resultam em um produto.

Desta forma, o presente trabalho busca mostrar como o designer pode atuar de maneiras diversas e aparentemente opostas, como as implicações que tecnologias avançadas trouxeram para a produção de objetos na era da informação e ao mesmo tempo com um resgate de técnicas manuais e tradicionais que exigem habilidades manuais e muito tempo de produção, prática que vai contra a lógica de muitas empresas do mundo globalizado.

\section{Processos de Fabricação Digital e o Impacto na Relação "criador e criatura"}

Com o surgimento das primeiras indústrias no século XIX, as oficinas e corporações de ofício foram progressivamente tornando-se obsoletas como meios de produção, e pouco tempo depois, a segunda Revolução Industrial gerou grande preocupação com a possibilidade de uma iminente substituição da mão-de-obra humana pela máquina. Em pleno século XXI, ainda é possível perceber os mesmos questionamentos com as mudanças trazidas pela implantação de novas tecnologias: desta vez a fabricação digital tornará o trabalho manual obsoleto?

O "mundo real" descrito por Papanek já não é o mesmo, sobretudo porque a explosão do meio digital nos últimos 25 anos tem transformado profundamente o panorama econômico, político, social e cultural. A conectividade da contemporaneidade faz parte do cotidiano de todos, o homem é incapaz de pensar o mundo sem o uso de computadores e da internet, e "hoje em dia não há como ser 'contra o sistema', pois construímos um mundo que quase nada existe fora do domínio do artificial" (CARDOSO, 2012, p. 12). Foi construída uma realidade complexa e 
interconectada, de forma que é preciso atentar para o papel de cada elemento dentro deste sistema: criação, produção e consumo de artefatos (materiais e imateriais).

A introdução de tecnologias a cada revolução industrial transforma não só os meios de produção como a sociedade como um todo, pois os modelos implantados determinam, também, os modelos mentais e comportamentais da sociedade. Diversos autores anunciaram a 3a Revolução Industrial (TOFFLER, 1981; GERSHENFELD, 2005; ANDERSON, 2010; RIFKIN, 2011; TROXLER, 2013), uma revolução desencadeada na metade do século XX - e consolidada atualmente por advento da internet e disseminação de computadores pessoais - no cenário pós-guerra, marcada por um profundo e contínuo progresso da tecnologia, motivada principalmente pelo conhecimento científico e pela produção industrial.

Há quem já fale de uma nova revolução (HAWKEN et al, 2013; SCHWAB, 2017), a 4a Revolução Industrial ou Indústria 4.0. Tal revolução é associada aos processos de industrialização smart, indústrias inteligentes que conectam o cyber com o físico, como a internet das coisas ${ }^{1}$ (the internet of things) e a automação. Apesar do que o nome possa indicar, não se espera que esta revolução irá substituir totalmente o modelo de manufatura atual, mas ela possui capacidade de produzir bens materiais assim como as indústrias, utilizando informações de dados de computadores na materialização dos artefatos.

Cardoso (2012) ressalta que ainda na década de 1960 o paradigma estava fincado em uma produção massificada, com grandes tiragens de um mesmo produto para atender a todos os consumidores, sem distinção. Atualmente é possível perceber o direcionamento para uma produção mais flexível, com a diversificação dos setores e que almeja atender demandas distintas através da adaptação no desenvolvimento de seus projetos. Pesquisadores como Gershenfeld (2012) acreditam que a fabricação digital permitirá que todas as pessoas projetem e produzam objetos tangíveis sob demanda, onde e quando precisarem. Tal projeção está se concretizando, uma vez que é possível observar o número crescente de fab labs e equipamentos como impressoras 3D domésticas com preços cada vez mais acessíveis.

O amplo acesso às tecnologias poderia desta forma desafiar verdadeiramente o sistema, os modelos tradicionais de negócio, investimentos e educação. Graças aos avanços tecnológicos, hoje é possível trocar informações sobre design e processos de fabricação, permitindo que designers, consumidores e fabricantes reduzam o tempo entre concepção e produção (VALLANCE et al., 2001). É fato que a tecnologia atual traçou um caminho sem volta, mas a questão é: como fazer uso e significar esses processos?

As novas tecnologias têm contribuído para modificar os comportamentos "mentais" que cada um tem absorvido como novos parâmetros do pensar, do decidir e do avaliar. A capacidade e a paixão combinatória típica do "corta e cola criativo", a velocidade relacional do SMS, o compartilhamento de projetos do file-sharing, o aprofundamento narrativo do DVD, a exploração personalizada do território típica do GPS, a memória seletiva possível com o iPod, as formas do do-it-yourself de convívio típicas do vídeo fotografia digital, a experimentação expressiva dos Djs ou o imediatismo instintivo e gestual dos tablets têm indicado o caminho, partindo da concretude das práticas de vida e da força propositiva dos novos esquemas mentais. Esses esquemas vão em direção ao universo do consumo autoral. (MORACE, 2009, p. 17)

\footnotetext{
1 De maneira geral, a "internet das coisas" se refere à interconectividade de objetos do cotidiano que usualmente são providos de sistemas inteligentes apoiados na internet.
} 
Desta forma, ainda que Morace (2009) aponte as transformações proporcionadas pela inserção do meio digital no nosso cotidiano, ressalta que este tipo de relação pode gerar um consumo cada vez mais pessoal, ou seja, todas as noções de pertencimento que o indivíduo projeta em um artefato irão ganhar uma nova dimensão com as informações trocadas através da conectividade. A participação ativa do consumidor/usuário no processo de criação e produção além de proporcionar objetos únicos e exclusivos, pode também ser uma alternativa de menor impacto ambiental em relação a certos processos produtivos por evitar emissão de poluentes com transporte e diminuir gastos por produzir quantidades menores e de acordo com a demanda.

Tal modalidade de consumo e produção já é realidade na chamada cultura maker, com diversas plataformas online que disponibilizam projetos tanto para o usuário executar sozinho como encomendar sua produção. Ao consumidor/usuário deste tipo de serviço é dado o nome de prosumer, que deriva do termo prosumption² (production by consumers), que seria algo como "produção pelo consumidor". Outra alternativa é a produção em fab labs, espaços que disponibilizam as ferramentas de prototipagem para fabricação pessoal, onde é possível qualquer usuário alugar seu uso e participar de cursos para o desenvolvimento e feitura dos objetos.

Em crescente expansão ao redor do mundo, os fab labs tiveram sua origem no MIT (Massachusets Institute of Technology) com a disciplina "How to make (almost) everything", ou "como fazer (quase) todas as coisas", do professor Neil Gershenfeld. Ele defendia que as as pessoas comuns com as ferramentas certas poderiam desenvolver e construir qualquer coisa, usando a tecnologia para criar, experimentar e produzir. Além do espaço físico, os fab labs promovem uma comunidade que possibilita a troca de informações e cooperação para os projetos.

Figura 01 - Crianças projetando em oficina no Fab Lab Recife

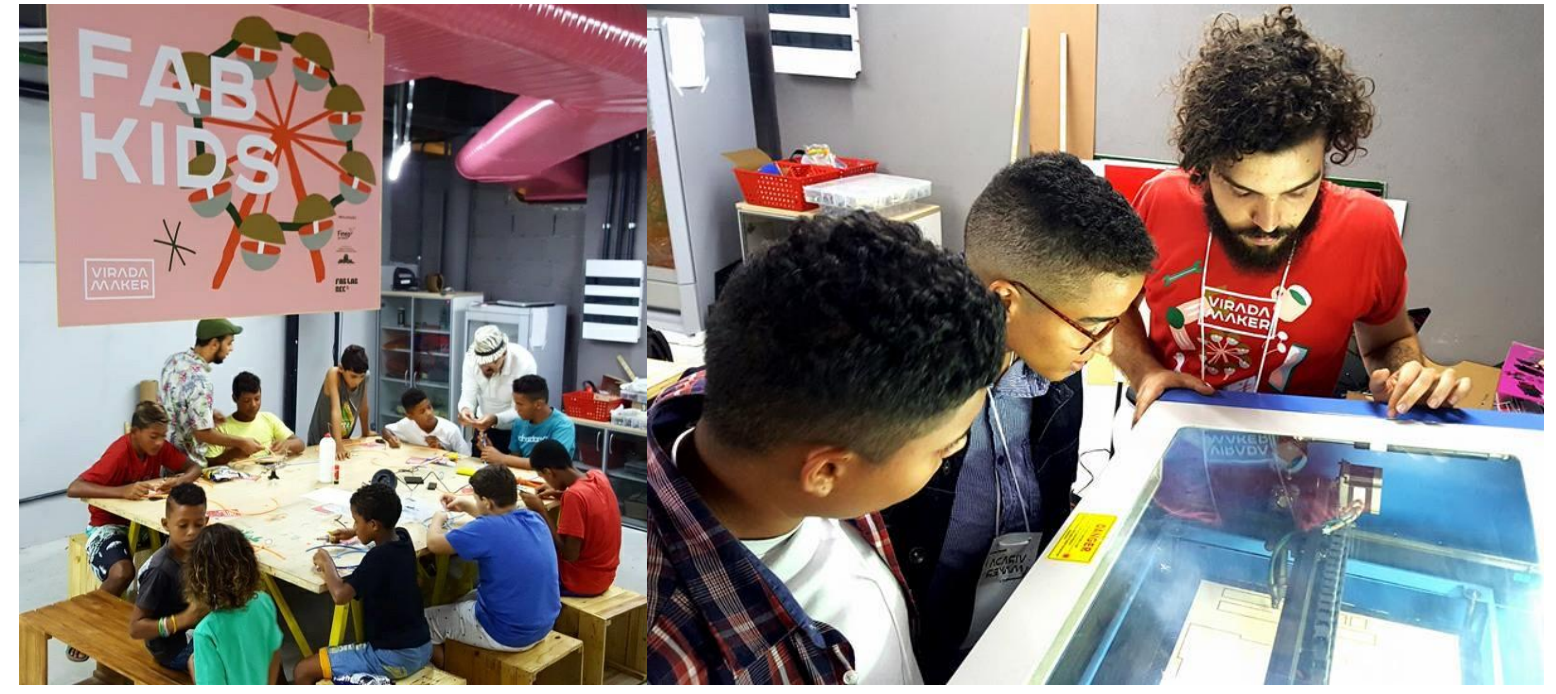

Fonte: https://www.facebook.com/pg/FabLabRecife

Os estúdios de design também fazem uso de tais recursos, a exemplo do Nervous System, fundado em 2007. Utilizando o processo de simulação computacional para criar seus projetos e

\footnotetext{
${ }^{2}$ Esta terminologia é baseada no termo cunhado por Alvin Toffler em seu livro A terceira onda (The third wave, 1980).
} 
processos de fabricação digital de produtos, como a impressão 3D, corte a laser e CNC (comando numérico computadorizado), sua principal fonte de inspiração são os elementos da natureza. Seus projetos são comercializados através de um aplicativo que permite a interação e co-criação por parte do cliente. Algumas de suas peças fazem parte da coleção permanente de museus, como o Museum of Modern Art, Cooper-Hewitt, Smithsonian Design Museum, e o Museum of Fine Arts em Boston.

Com seu projeto Kinematics (Figura 02), o estúdio utiliza um sistema para impressão que cria formas complexas e dobráveis, compostas por módulos articulados. Desta forma, é possível transformar qualquer forma tridimensional em uma estrutura flexível usando a impressão 3D, combinando técnicas de geometria computacional com física e personalização. São produzidos desenhos que possuem de 10 a 1000 componentes, e estes se interligam para construir estruturas mecânicas dinâmicas onde cada modulo é rígido, mas na estrutura geral, o conjunto se comporta como um tecido contínuo. Através do site o usuário é capaz de definir os parâmetros de sua peça de acordo com seu corpo, tornando-a única e personalizada.

Figura 02 - Peças de vestuário Kinematics

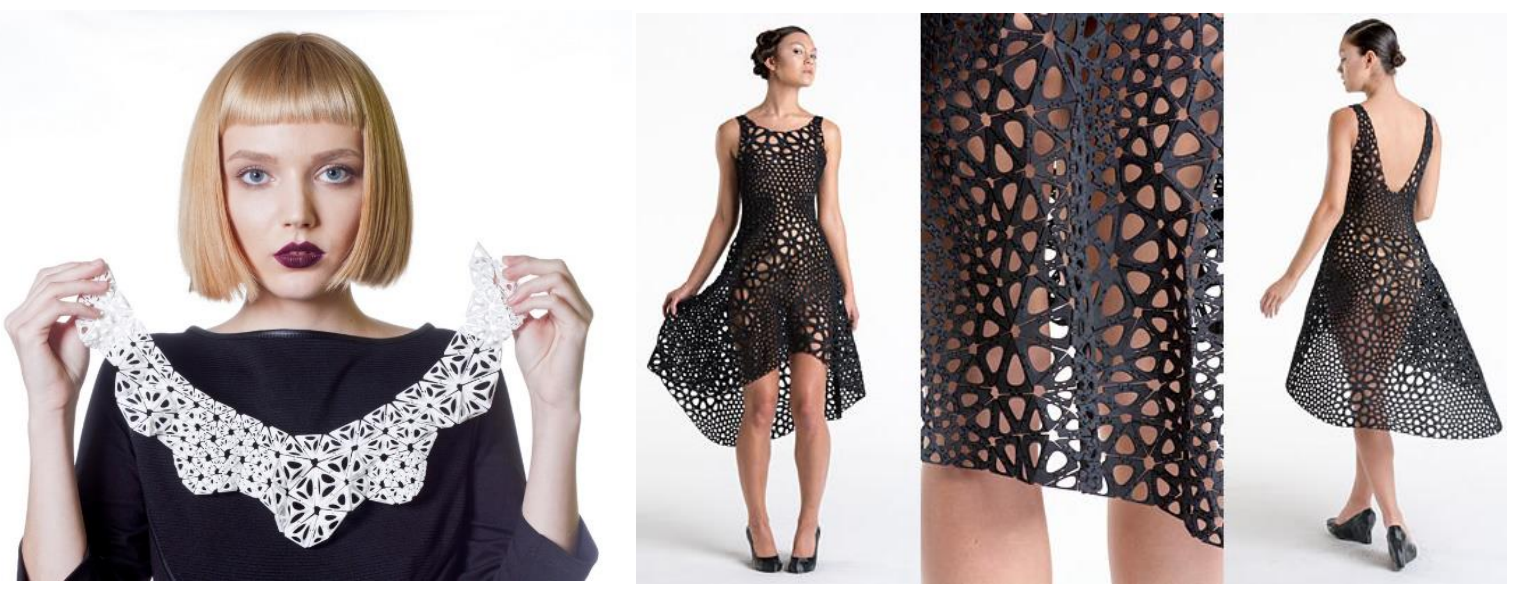

Fonte: https://n-e-r-v-o-u-s.com

A Shapeways é uma comunidade de fabricação digital online que abriga tanto a projetos de designers como de um usuário comum. No site é possível executar algumas peças através de uma interface simplificada e intuitiva, sem a necessidade do domínio de softwares de modelagem. 0 usuário escolhe a forma, cor, material e tratamento superficial de suas peças e encomenda o produto no conforto de sua casa. É possível fazer upload de projetos mais elaborados e executá-los, bem como colocá-los à venda na área de mercado ao montar uma loja. A plataforma também media a contratação de designers para projetos específicos. 
Figura 03 - Opções de materiais e aplicações da plataforma Shapeways
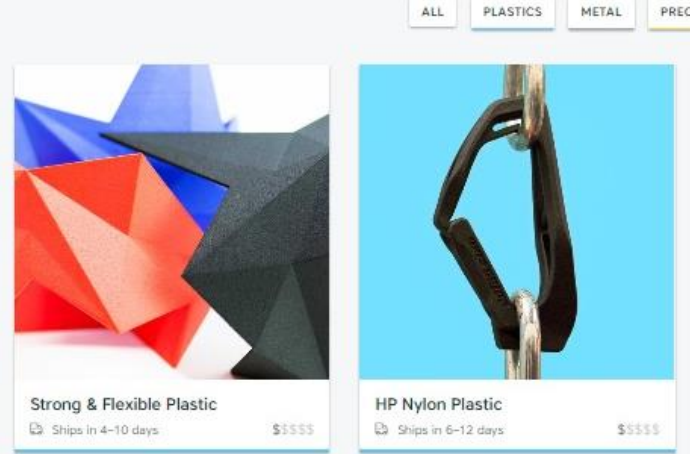

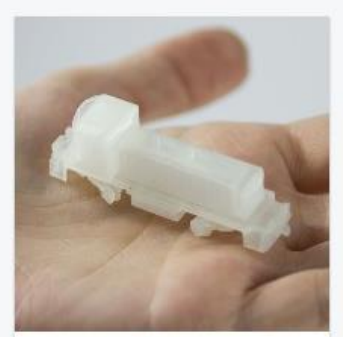

Frosted Detail Plastic

Frosted Detail Plastic
B. $\operatorname{ships} 33-6$ dars

Fonte: https://shapeways.com

Cardoso (2012) prediz que no mundo complexo atual os designers terão que se libertar do seu "legado profissional" e aprender a trabalhar em rede, que não seria possível trabalhar unicamente de forma isolada e unilateralmente autoral. Esta constatação abre espaço para diversas reflexões sobre a relevância da autoria e propriedade de uma ideia na era da informação. Qual o real papel do designer na contemporaneidade quando o consumidor é parte atuante do processo criativo e as tecnologias de produção não pertencem mais, exclusivamente, às indústrias? Quem será o "criador" e a "criatura"?

\section{O Flerte com o Artesanal e o "Design Lento"}

No outro espectro do meio produtivo há o crescente grupo de designers que atuam de maneira autoral e rumam para um processo cada vez mais manual, mais próximo do que era esperado de um mestre artesão da corporação de ofícios: ativo e ciente de todos os processos de concepção e produção de seus artefatos. Desligados do ambiente industrial tradicional e adeptos à autoprodução, o designer gerencia a concepção, produção, distribuição, publicidade e venda de seus produtos. Isso quer dizer que o designer tem total controle sobre o desenvolvimento de seus projetos, ou seja, uma liberdade criativa e projetual em um nível que provavelmente não teria ao estar subordinado a uma indústria.

Por mais que sejam reconhecidos processos pelo mundo, a Itália é a maior produtora de conhecimento sobre o fenômeno, e lá foi identificada a tendência de designers custearem a produção de certos produtos mais laboriosos que as empresas não possuem interesse ou capital para levar adiante. Este processo vem ganhando expressividade no mercado por poder agregar mão de obra local e promover uma produção de menor impacto ao ambiente quando comparada à industrial. Cada vez mais ganha adeptos e já conta com eventos internacionais que promovem a atividade, como a feira Operae que ocorre em Torino, Itália.

O flerte com o artesanal, apesar de não ser novidade - a exemplo das experimentações tecnológicas dos anos 1920 e 1930, ou do design italiano das décadas de 1970 e 1980 - ganhou novo fôlego com jovens designers londrinos na década de 1990, e pode ser encontrado em vários redutos, como no abundante mobiliário de produção autoral do Palermo Viejo, em Buenos Aires (PASCA; TRAPANNI, 2002). No Brasil, a valorização do manual pelo design é um pouco recente, mas se mostra bastante presente em vários setores, como a moda e o mobiliário, por exemplo. Há de se 
destacar que no país - assim como em outros da América latina - há o estímulo do uso da mão de obra artesanal ou de habilidades manuais no design como incentivo cultural e social por se mostrarem uma alternativa de ocupação e geração de renda para parte da população.

Mas o que pretende-se destacar aqui é a produção manual por parte do designer, que escolhe deliberadamente trilhar este caminho com sua produção em detrimento de processos mais modernos, consequentemente mais rápidos e que proporcionem uma tiragem maior de produtos. O designer brasileiro Ricardo Graham - que se auto intitula "o Ebanista" - foi buscar formação tradicional de marcenaria, tornando-se aprendiz de mestre artesãos no Centro di Formazzione Professionale Giuseppe Terrazani no sul da Itália, e posteriormente, formação superior em ebanesteria na École Supérieure d'Ebanesterie em Avignon, França.

Graham abriu sua oficina no Rio de Janeiro, onde trabalha com madeiras maciças tropicais provenientes de manejo sustentável e faz uso de técnicas tradicionais da marcenaria, como fixar suas peças usando encaixes com a própria madeira. As borboletas, cunhas e gravatas acabam servindo como elementos estéticos nos produtos, e para o acabamento de seus móveis utiliza apenas materiais naturais como cera e óleos vegetais.

Seus produtos são vencedores de prêmios de design como o A'Design Awards, e participaram de feiras e exposições importantes como o Salão do Móvel em Milão. São executados minuciosamente, com detalhes que exigem técnica e tempo de execução. O premiado banco Sela (Figura 04) foi desenvolvido através de testes e de maneira escultural, passando longe da forma engessada das medidas antropométricas padrão, como um artesão que conhece o seu ofício e tem prazer em exercê-lo.

Figura 04 - Ricardo Graham produzindo o banco Sela

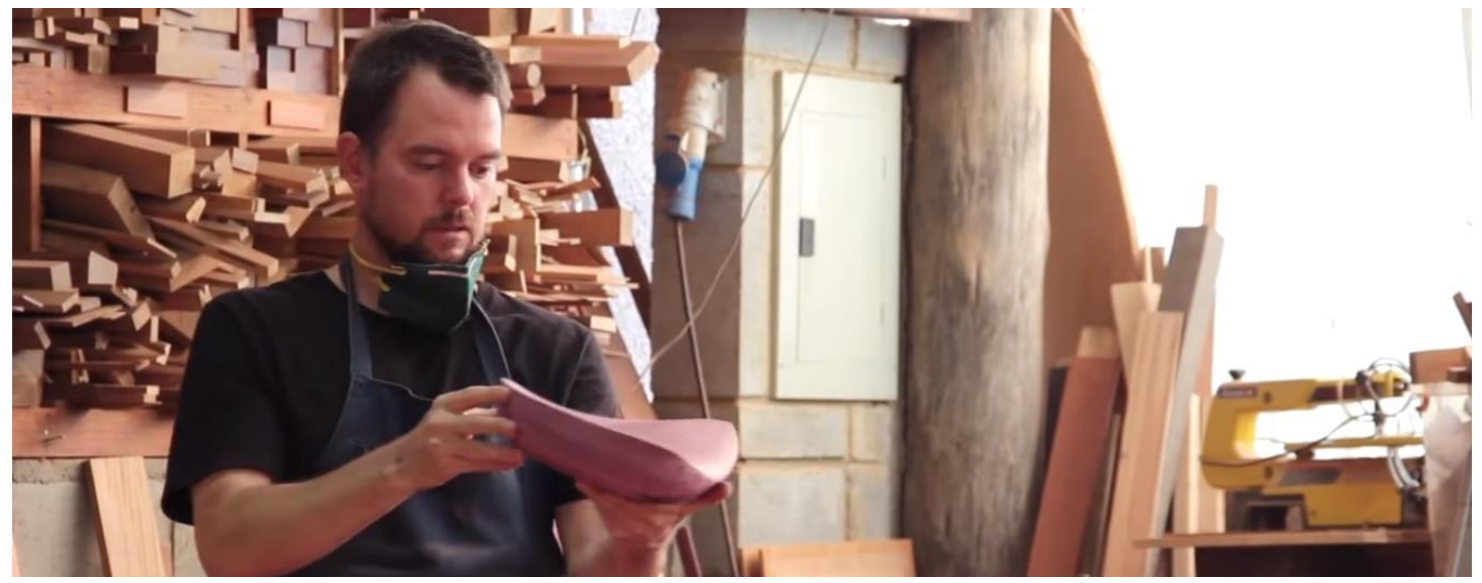

Fonte: http://www.oebanista.com.br 
Figura 05 - Detalhes de peças d'o Ebanista
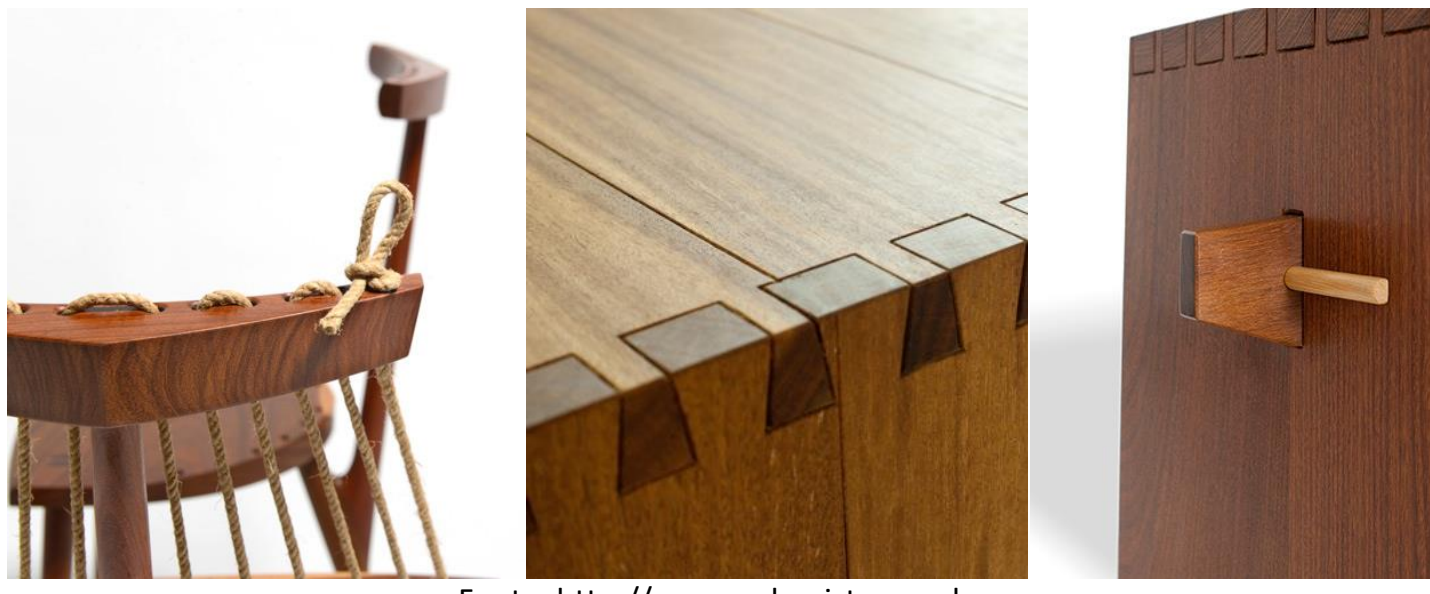

Fonte: http://www.oebanista.com.br

Já a brasileira Inês Schertel é adepta do slow design. O slow design (algo como "design lento) é uma atividade que vai além do ato de projetar, é uma abordagem que encoraja um processo mais "lento", considerando o bem-estar dos indivíduos, da sociedade, do ambiente e da economia. Posiciona-se contra o paradigma atual da produção acelerada, que é regida por um ciclo insustentável de modismo e consumo exacerbado, de ética questionável e uma antropologia que define todas as pessoas como consumidores. O uso do termo "slow" (devagar, lento) como adjetivo ou advérbio gera uma ambiguidade proposital, implicando que o tempo está implícito em todas as facetas do design, e que seu propósito é "desacelerar" o processo, seu resultado e os efeitos que ele causa (FUAD-LUKE, 2008, p. 361).

Arquiteta por formação, Inês viu na feltragem tradicional uma maneira de trabalhar com a lã resultante da tosquia da criação de ovelhas do marido, trocando a carreira e a casa em São Paulo pela fazenda no Rio Grande do Sul. Buscou aprimorar-se na técnica milenar da feltragem de lã com cursos na Europa e em uma temporada com artesãos de uma tribo nômade do Quirguistão.

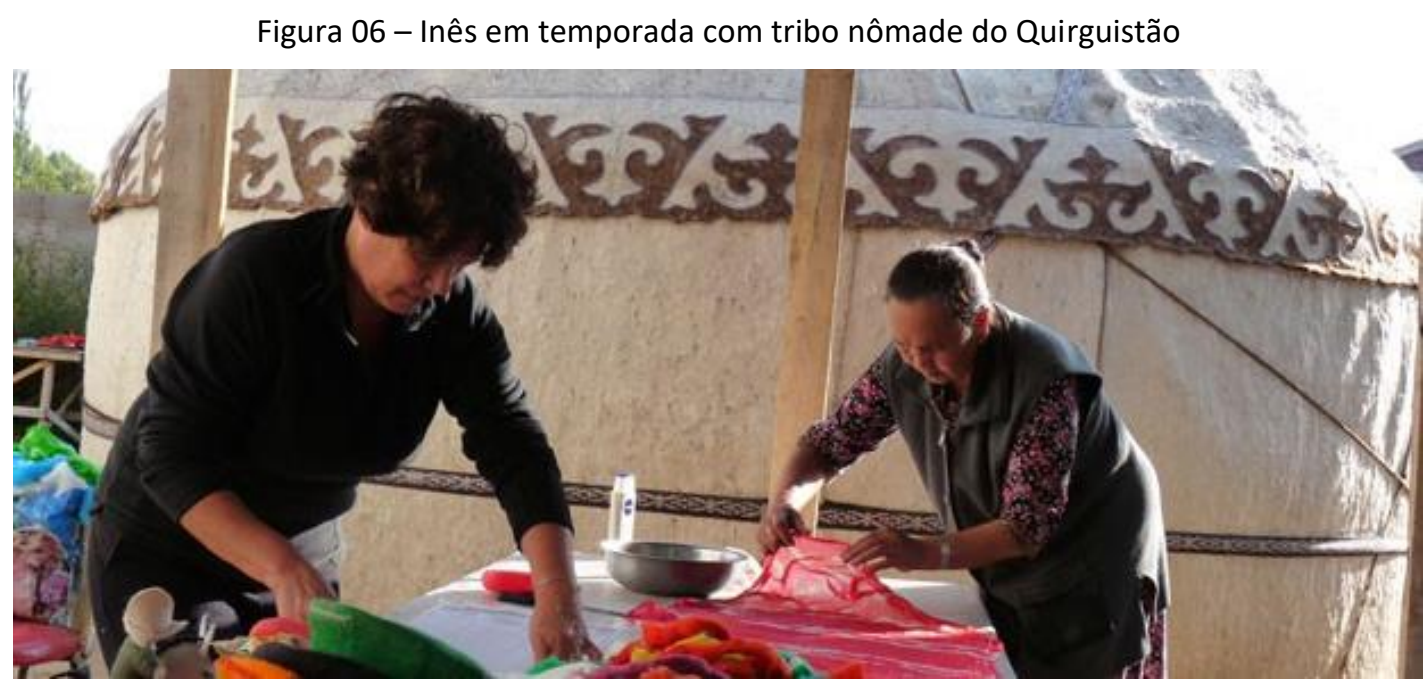

Fonte: http://casavogue.globo.com/Design 
Depois da tosquia, Inês trata a lã e fabrica o feltro manualmente em um processo que consiste em pressionar a lã com sabão de oliva e água, onde as fibras encolhem e se aglomeram. 0 feltro então é moldado e pode ser tingido, de preferência com elementos vegetais da própria fazenda, dando forma a toda uma sorte de produtos. Suas peças participaram do Salão do Móvel de Milão da exposição Slow Design, em Portugal.

Figura 07 - Produtos Inês Schertel
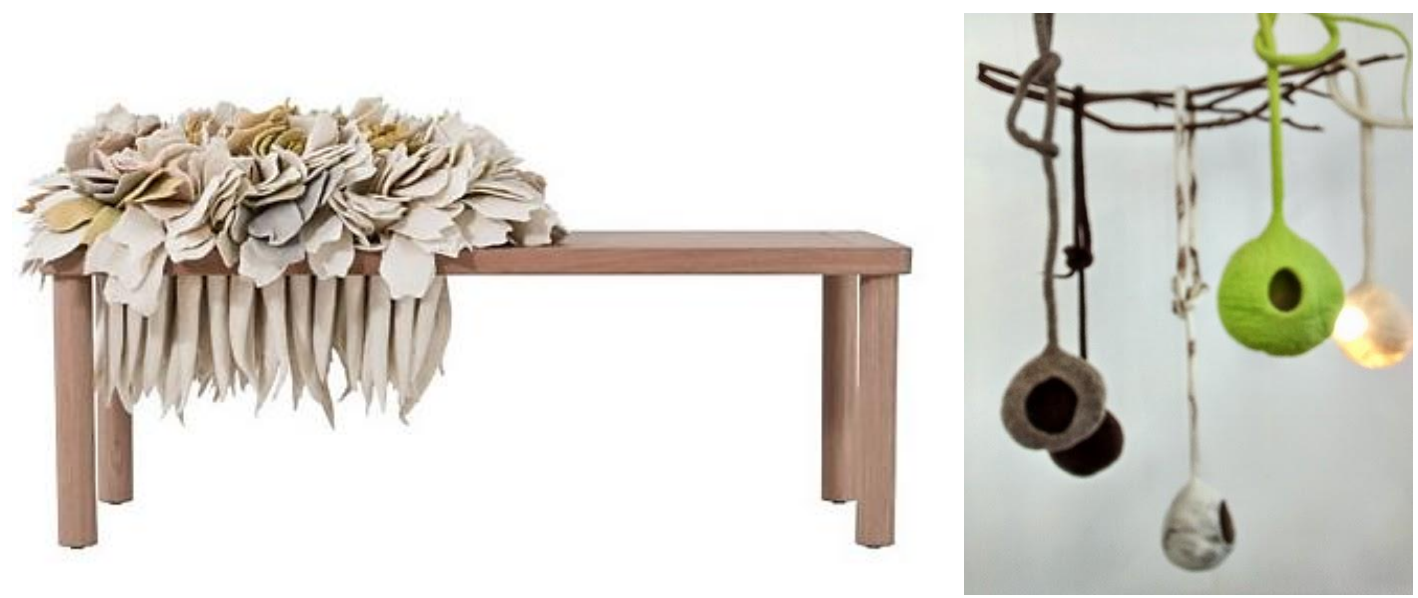

Fonte: http://www.inesschertel.com.br

Os objetos são concebidos, produzidos e consumidos norteados pelas relações das pessoas envolvidas no processo. Se a tecnologia é uma invenção humana, não é possível dissociá-la das suas relações sociais. Isso quer dizer que a tecnologia empregada na produção dos artefatos de design leva em consideração diversos fatores, assim como refletem o posicionamento de quem os concebe. Ono (2012) cita as dimensões política, cultural, econômica e social regendo esse fenômeno, esta última composta de outros fatores presentes na vida social, como a história, a ética, a arte, a religião, ideologias, etc.

Desta forma, é possível inferir que diversos fatores levam à escolha da produção manual. Há o posicionamento bem definido como é visto no slow design, a escolha pessoal de um aprimoramento no ofício, como também existe a experimentação do manual dialogando com outras formas de produção. Alguns designers recorrem ao processo artesanal para executar seus projetos e posteriormente vendê-los para empresas de maior porte que os farão em maior tiragem. Um exemplo notável é a produção dos Campana, que criam manualmente os protótipos em seu ateliê e comercializam suas peças para empresas como a italiana Edra.

Já a indústria automobilística, por mais que tenha acesso a softwares de última geração e uma produção extremamente mecanizada, ainda recorre à modelagem manual escultórica em clay (argila) para seus modelos em desenvolvimento. O contato com o manual ainda é importante, e ao contrário do que parece ser inevitável, não precisa ser substituído pelo digital. Eles podem seguir juntos. 


\section{Considerações Finais}

Pode-se concluir que a falsa dicotomia do antiquado e do moderno, manual e digital, não funciona na prática do design. Encarar o design como uma evolução do artesanato, associando o fazer manual ao primitivo e ao industrial à representação do desenvolvimento tecnológico como se conhece hoje, pode levar à falsa impressão de que um caminho deve ser seguido em nome do progresso e o outro deve desaparecer.

Há espaço para atender necessidades tão distintas da sociedade e do próprio design concomitantemente, tanto o experimento com as novas possibilidades tecnológicas como a busca consciente de um processo enraizado no tradicional, que explora o sentido do ofício ao tratar da matéria prima, do seu beneficiamento e das técnicas de produção para transformá-la em artefato. As atividades aqui descritas brevemente compõem mais um desdobramento da atuação do designer na contemporaneidade, e estas podem dialogar entre si formando novas práticas.

A dinâmica do desenvolvimento de artefatos está em constante mudança, o papel do designer neste processo é se adaptar às necessidades, usar de seu conhecimento para promover este processo, mesmo que servindo de ponte, como visto na produção via usuário. As ferramentas e o processo produtivo são apenas meios de materializar o que o designer sabe fazer: criar.

\section{Referências}

BAUMAN, Z. A cultura no mundo líquido moderno. Rio de Janeiro: Zahar, 2013.

CARDOSO, R. Design para um Mundo Complexo. São Paulo: Cosac Naify, 2012.

CARVALHAL, A. Moda com propósito: manifesto pela grande virada. 1a Ed. São Paulo: Paralela, 2016.

FERRARA, M. Design and self-production: the advanced dimension of handcraft. Strategic Design Research Journal, vol. 4, n. 1, p. 5-13, 2011.

FUAD-LUKE, A. Slow design. In: EHRLHOFF, M.; MARSHALL, T. (ed.) Design Dictionary: perspectives on Design Terminology. Basel: Birkhäuser, 2008. p. 361-363.

GERSHENFELD, N. How to make almost anything the digital fabrication revolution. EUA: Foreign Affairs, 2012.

HAWKEN, Paul, AMORY B. Lovins e LOVINS L. Hunter. Natural capitalism: The next industrial revolution. Routledge, 2013.

MORACE, F. Consumo autoral - as gerações como empresas criativas. Tradução de Kathia Castilho. São Paulo: Editora Estação das Letras e cores, 2009.

NIINIMÄKI Kirsi (ed.) (2013). Sustainable Fashion: new approaches. Aalto University publication series, Art + Design + Architecture 9/2013, Aalto ARTS Books: Helsinki, Finland.

ONO, M. Design e cultura: sintonia essencial. Curitiba: Serzegraf, 2006.

OSTROWER, F. Criatividade e processos de criação. Petrópolis: Vozes, 1978.

PARSONS, T. Thinking objects: contemporary approaches to product design. Switzerland: Ava, 2009. 


\section{Artigo Completo}

PASCA, V.; TRAPANI, V. Scenari del giovani design: Idee e progetti dall'Europa e del mondo. Milão: Lupetti, 2002.

TOFFLER, ALVIN. A terceira onda: a morte do industrialismo e o nascimento de uma nova civilização. Rio de Janeiro: Record, 1981.

SCHWAB, Klaus. The fourth industrial revolution. Crown Business, 2017.

VALLANCE, Ryan; KIANI, Sepehr e NAYFEH, Samir. Open design of manufacturing equipment. Proceedings of the CHIRP 1st International Conference on Agile, Reconfigurable Manufacturing, 2001. 